Ärztliche Erfahrung beschränkt sich nicht auf medizinisches Fachwissen.

\title{
Zwangseinweisung? Den Spieß dreht der Patient um!
}

Im Notdienst wurde ich um Mitternacht zu einem psychiatrischen Notfall gerufen. Als wir eintrafen, standen bereits zwei Polizei- und ein Rettungswagen vor dem Haus. Schon von unten konnte man eine lautstarke, dominante Stimme hö-

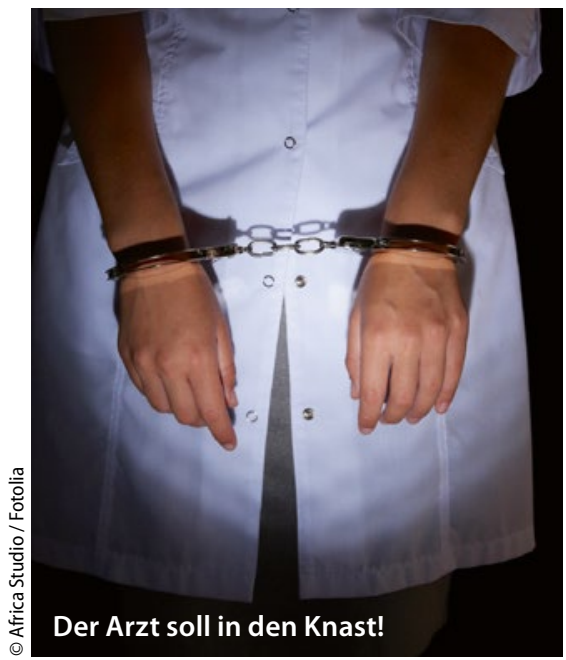

ren. Ein Sanitäter erklärte mir, dass der Patient gegenüber seiner Frau und seiner Tochter aggressiv gewesen sei und eine bipolare Erkrankung bekannt sei. Ich stellte mich dem Patienten vor und fragte, was vorgefallen sei. Er musterte mich distanziert und antwortete, dass nichts passiert sei und man ihn gefälligst in Ruhe lassen solle. Da die Situation aktuell nicht sehr gefährlich schien, bot ich ihm ein Sedativum an, das er harsch ablehnte.

Nun wandte ich mich an seine Frau und seine Tochter, die sich in einem anderen Zimmer eingeschlossen hatten. Sie wirkten sehr eingeschüchtert. Der Mann habe seit Tagen keine Tabletten genommen, sei in einen Kaufrausch verfallen und habe sich verschuldet. Vor allem aber bedrohe er sie.

Da die Situation nicht tragbar war, bot ich dem Patienten eine stationäre Einweisung in die Nervenklinik an, die er kategorisch ablehnte. Ich eröffnete ihm, dass er trotzdem von einem Psychiater gesehen werden müsse, da eine Eigen- und Fremdgefährdung vorliege. Er weigerte sich weiter. Letztlich überzeugten ihn wohl die vier bereits anwesenden Polizisten, „freiwillig“ mitzugehen - nicht ohne dass er schimpfend ankündigte, bald wieder zurück zu sein.

Zwei Wochen später erhielt ich einen Anruf der Polizei. Man teilte mir mit, ge gen mich läge eine Strafanzeige wegen Freiheitsberaubung vor. Dies verärgerte mich natürlich, obwohl ich es für unwahrscheinlich hielt, dass ein Richter aus meiner Einweisung eine Freiheitsberaubung ersehen könnte. Aber man weiß ja nie genau! Nach einigen Wochen erhielt ich ein Schreiben, dass das Verfahren eingestellt sei. Innerlich atmete ich auf. Der Richter hatte den Fall für eindeutig gehalten und mir weitere Mühe erspart.

Dr. Rainer Hakimi, Stuttgart

\section{Das Mädchen mit den mysteriösen „Hebbl an dr Mu“}

_ Nach 25 Jahren Landarztdasein am Fuße der schwäbischen Alb war ich eigentlich überzeugt, mit der schwäbischen Sprache vertraut zu sein - zumal ich, nebenbei bemerkt, auch dort aufgewachsen bin. Eines Tages betrat jedoch eine junge Mutter die Praxis und eröffnete mir, ihre Kleine habe „Hebbl an dr $\mathrm{Mu}$ “! Mit „Hebbl“ konnte ich noch etwas anfangen; so bezeichnet man im Schwabenland z. B. Schwellungen nach Insektenstichen, erhabene Hautstellen oder auch mal Flecken auf der Haut. Wer oder was mit der "Mu“ jedoch gemeint sein könnte, erschloss sich mir auch nach längerer Überlegung nicht.

Die Mama, die selbst aus Sachsen stammte, bemerkte meine Ratlosigkeit und entschloss sich, mir einen Tipp zu geben, indem sie kurzerhand den Ort des Problems freilegte: Die Kleine hatte eine Genitalmykose mit den bekannten Satellitenabsiedlungen. Bei diesem Problem an der „Mu“ konnten wir ohne Weiteres Abhilfe schaffen.

Dr. Reinhard Sattler, Heiningen 